\section{Fórum: saúde e povos indígenas no Brasil. Posfácio}

\author{
Forum: health and indigenous people in Brazil. \\ Postscript
}

\author{
Foro: salud y pueblos indígenas en Brasil. \\ Epílogo
}

${ }^{1}$ Centro de Pesquisas Leônidas \& Maria Deane, Fundação Oswaldo Cruz, Manaus, Brasil.

Correspondência L. Garnelo

Centro de Pesquisas Leônidas

\& Maria Deane, Fundação Oswaldo Cruz.

Rua Terezina 476, Manaus, AM 69057-070, Brasil. luiza.garnelo@amazonia. fiocruz.br
Diversidade homogeneizada: para onde caminha o Subsistema de Saúde Indígena?

Os resultados apresentados no painel Saúde $e$ Povos Indígenas no Brasil: Desafios Nacionais e Insights Locais expressam olhares múltiplos sobre realidades locais diversificadas, formando um mosaico capaz de exprimir, simultaneamente, situações comuns e singulares nas condições de saúde de populações indígenas no território nacional.

James Welch, coordenador do painel, rememora um depoimento indígena ali enunciado, no qual as cores vívidas do cotidiano despontam com força, remetendo-nos às dificuldades sanitárias enfrentadas pelos povos indígenas. Aquilo que a linguagem da saúde pública designa por termos assépticos como dificuldade de acesso, baixa resolutividade, baixa efetividade, elevadas taxas de morbimortalidade e outros conceitos correntes no nosso campo de trabalho transmuta-se, na voz xavante de Supretaprã, em dores e humilhações sofridas no dia a dia em busca de atenção à saúde, nos duros quilômetros percorridos em busca de água potável não ofertada nas aldeias, no inútil peregrinar dos doentes crônicos que recebem atendimento sem conforto, sem dignidade e sem meios diagnósticos e terapêuticos adequados, e que entram e saem de unidades de saúde mais confusos e, muitas vezes, mais doentes do que estavam ao adentrar nelas.
Luiza Garnelo ${ }^{1}$

A fala de Supretaprã vem do Distrito Sanitário Especial Indígena (DSEI) Xavante, no centro do Brasil, mas seu teor guarda forte semelhança com a dos pesquisadores que também se apresentaram no painel. É o caso de Diehl \& Pelegrini que evidenciam importante contradição internas nas diretrizes institucionais que orientam a formação e qualificação da força de trabalho alocada no Subsistema de Saúde Indígena (SASI). Com eles aprendemos que a Política Nacional de Saúde Indígena (PNASPI) enfatiza a necessidade de formação e qualificação dos profissionais indígenas, mas na PNASPI seu perfil é limitado à categoria dos agentes indígenas de saúde. Por outro lado, guias importantes da condução técnica, política e operacional como as Conferências de Saúde - em particular a $4^{\text {a }}$ Conferência Nacional de Saúde Indígena - tratam genericamente de diretrizes para a qualificação para indígenas e não indígenas, mas as recomendações do relatório final direcionam-se primordialmente para subsidiar a atuação da força de trabalho não indígena. É digno de nota que as diretrizes institucionais do SASI ignorem o crescimento expressivo do número de profissionais indígenas de nível médio e superior, os quais vêm sendo formados no Brasil no âmbito da educação escolar indígena e da política de cotas que ampara o acesso das minorias étnicas às vagas nas universidades.

Diehl \& Pelegrini demonstram que também no plano operacional os dispositivos normativos não têm se traduzido em ações capazes de efetivar 
a propalada sensibilidade cultural, tema designado, nos documentos oficiais, pelo termo atenção diferenciada. Tomando como exemplo pesquisas realizadas em DSEI localizados no Sul-Sudeste, no Centro-oeste e na Amazônia, Diehl \& Pelegrini mostram que tais realidades são diversas, tendo em comum o etnocentrismo; o desconhecimento das culturas indígenas e da historicidade que permeia a vida contemporânea nessas sociedades; o despreparo para lidar com a alteridade; e a homogeneização das práticas sanitárias calcadas em ações biomédicas de baixa resolutividade e elevada descontinuidade. A distribuição e alocação dos profissionais de nível superior nos DSEI são congruentes com o perfil das já conhecidas desigualdades regionais, porém carecem de iniciativas capazes de reduzir as iniquidades de acesso e de oferta de serviços de saúde nas terras indígenas, mesmo após quinze anos de implantação da política de saúde indígena.

Tomando como base fontes documentais relativas à consultoria encomendada pelo Ministério da Saúde, Marina Cardoso empreende uma verdadeira arqueologia dos fundamentos éticos e políticos da PNASPI, ampliando o entendimento do cenário acima descrito. A argumentação e conclusões de Cardoso indicam que a institucionalização do SASI tanto padece de uma adequada concepção dos modelos assistencial e operacional, quanto de práticas organizativas capazes de responder aos desafios e necessidades de estender a cobertura assistencial a regiões remotas, ou mesmo às aldeias geograficamente próximas, mas também com baixo acesso às políticas públicas. A autora aponta problemas já antigos - mas nunca superados pelos órgãos de governo - que remetem à incapacidade do gestor federal em prover diretamente a atenção à saúde à população indígena sob sua responsabilidade sanitária, perenizando a estratégia de terceirização das ações, mediante a adoção de convênios e / ou de compra de serviços de entidades não governamentais e de sistemas municipais de saúde. Tais práticas de gestão têm ferido princípios fundamentais do SUS como a universalidade, a integralidade e a garantia de acessibilidade plena por intermédio da rede de atenção primária à saúde e se mostrado incapaz de garantir a continuidade na prestação de cuidados de saúde. É um cenário sugestivo de uma baixa institucionalização do SASI e de uma restrita capacidade gerencial e operacional da Secretaria Especial de Saúde Indígena (SESAI), atual gestora do SASI, que não dispõe de suficientes quadros próprios nem para gerir nem para executar as funções inerentes ao SASI.

Da análise de Cardoso destacamos temas relevantes como o do controle social, um conceito controverso que assumiu, no SUS, a conotação singular de controle das instituições pela sociedade, invertendo a noção sociológica clássica de controle e normalização das pessoas pelo estado 1. Estudos 2,3,4 sobre controle social no Brasil evidenciam que os conselhos de saúde no SUS enfrentam dificuldades em efetivar a expressão das necessidades dos grupos mais vulneráveis. Tais autores apontam avanços, contudo não negam que as estratégias vigentes de controle social terminam por ser excludentes e incapazes de propiciar a participação dos mais pobres, menos escolarizados, menos organizados politicamente e menos informados sobre seus direitos e necessidades em saúde.

As publicações disponíveis sobre controle social tratam - com raras exceções 5,6 - da participação de representantes do mundo não indígena nos conselhos de saúde, não se estendendo ao que ocorre no mundo indígena. A esse, à controversa noção de controle do Estado por meio da participação, deve se somar o fato de que conselhos de saúde são produções culturais oriundas e ordenadas pela lógica do colonizador. Ou seja, a participação indígena nos conselhos de saúde precisaria ser problematizada também à luz das relações interétnicas e da emergência do associativismo indígena como sujeito de direito e de representação junto ao poder público. Trata-se, portanto, de um cenário complexo que não encontra espaço na PNASPI e nem em outros documentos oficiais que orientam o controle social em saúde indígena.

Para Cardoso, as noções simplificadoras que, implícita ou explicitamente, ordenam a PNASPI geram desencontros conceituais e nas premissas que orientam tal política, estendendo a confusão ao plano vocabular, nos debates travados entre agentes do poder público e a política viva do associativismo indígena, participante preferencial nos fóruns do controle social. Nesse contexto, evidencia-se, como prática, o que Cardoso chama de "normatização inclusiva", uma modalidade homogeneizante de gestão e de prestação de serviços que ignora tanto as desigualdades sociais e sanitárias entre indígenas e não indígenas quanto a diversidade, inerentes ao modo de vida indígena e ao processo colonial instituído ao longo do contato interétnico. Assim, o SASI parece avançar às cegas, tendo pouco sucesso em efetivar as premissas que orientam sua concepção e se limitando a uma retórica que pouco se traduz em ação efetiva no interior das terras indígenas.

Se o SASI não tem conseguido efetivar a contento seus processos de gestão, tampouco tem sido capaz de subsidiar análises sistemáticas e qualificadas de indicadores de morbimortalidade e, muito menos, de reduzi-los a níveis con- 
gruentes com aqueles já alcançados pela população não indígena. Os dados disponíveis advêm de fontes de outra natureza 7,8, como o Inquérito Nacional de Saúde e Nutrição Indígena, aqui comentado por Carlos Coimbra Jr., que apresenta um contundente retrato da situação de saúde da população materno-infantil aldeada em terras indígenas. Os resultados desse inquérito evidenciam um cenário de iniquidades sociossanitárias exemplificado pelo alarmante déficit estatural e a anemia entre as crianças indígenas da amostra do inquérito (alcançando $40 \%$ e $51,2 \%$, respectivamente) em contraponto aos déficits que persistem entre as não indígenas $(5,5 \%$ e $20,9 \%$, respectivamente). É ainda mais surpreendente que esse perfil de iniquidades nutricionais seja tão evidente em regiões como a amazônica, onde o maior percentual de terras demarcadas e de cobertura vegetal nos levaria a esperar melhores níveis nutricionais que os encontrados na pesquisa.

O cenário apresentado por Coimbra Jr. conclui a sequência de elos necessários para fechar a corrente de eventos e propiciar o reencontro com o relato de Supretaprã. Aqui, as falas de pesquisa podem ser entendidas como traduções acadêmicas das situações relatadas pelo líder Xavante, remetendo a causas estruturais e conjunturais do cenário de iniquidades historicamente enfrentado pelos indígenas. Sua superação deveria ser auxiliada pelas políticas sociais emergentes, como a de saúde, todavia ela ainda não se mostrou capaz de apreender e aliviar o sofrimento vivido pelos indígenas em seu périplo diário na busca por cuidados de saúde.

\section{Referências}

1. Alvarez MC. Controle social: notas em torno de uma noção polêmica. São Paulo Perspect 2004; 18:168-76

2. Cortes SMV. Construindo a possibilidade da participação dos usuários: conselhos e conferências no Sistema Único de Saúde. Sociologias 2002; 7:18-49.

3. Labra ME, Figueredo JSA. Associativismo, participação e cultura cívica. O potencial dos conselhos de saúde. Ciênc Saúde Coletiva 2002; 7:537-47.

4. Moreira MR, Escorel S. Conselhos Municipais de Saúde do Brasil: um debate sobre a democratização da política de saúde nos vinte anos do SUS. Ciênc Saúde Coletiva 2009; 14:795-805.

5. Garnelo L, Sampaio S. Organizações indígenas e distritalização sanitária: os riscos de "fazer ver" e "fazer crer" nas políticas de saúde. Cad Saúde Pública 2005; 21:1217-23.
6. Garnelo L, Sampaio S. Bases socioculturais do controle social em saúde indígena: problemas e questões na Região Norte do Brasil. Cad Saúde Pública 2003; 19:311-7.

7. Coimbra Jr. CE, Santos RV, Welch JR, Cardoso AM, Souza MC, Garnelo L, et al. The First National Survey of Indigenous People's Health and Nutrition in Brazil: rationale, methodology, and overview of results. BMC Public Health 2003; 13:52.

8. Basta PC, Orellana JDY, Arantes R. Perfil epidemiológico dos povos indígenas no Brasil: notas sobre agravos selecionados. In: Garnelo L, Pontes AL, organizadores. Saúde indígena: uma introdução ao tema. Brasília: Secretaria de Educação Continuada, Alfabetização, Diversidade e Inclusão, Ministério da Educação; 2012. p. 60-106.

Recebido em 19/Mar/2014

Aprovado em 24/Mar/2014 